Seguridad Operacional y Logística Aeronáutica

Segurança Operacional e Logística Aeronáutica

Operational Safety and Aviation Logistics

\title{
LA LEGITIMA APLICACIÓN DEL DERECHO OPERACIONAL EN LOS PROCESOS CONTRA MILITARES A PROPÓSITO DE LA JURISDICCIÓN ESPECIAL PARA LA PAZ ${ }^{1}$
}

\author{
A LEGITIMA APLICAÇÃO DO DIRETO DE OPERAÇÃO NOS PROCESSOS CONTRA OS MILTARES COM RELAÇÃO \\ À JURISDIÇÃO ESPECIAL PARA A PAZZ2 \\ The Legitimate Applcation Of The Operational Law In Proceedings Against Miltary \\ For The Purpose Of The Special Jurisdiction For Peace ${ }^{3}$ \\ Jully Andrea Melo Lugo ${ }^{4}$ \\ Escuela Superior de Guerra
}

\author{
CIENCIA Y PODER AÉREO \\ ISSN 1909-7050 / E- ISSN 2389-2468 / Volumen 11 / Enero-diciembre de 2016/ Colombia/ Pp. $82-91$ \\ Recibido: 18/07/2016 \\ Aprobado evaluador interno: 10/09/2016 \\ Aprobado evaluador externo: 25/09/2016 \\ Doi: http://dx.doi.org/10.18667/cienciaypoderaereo.527
}


Para citar este artículo:

Melo, J. (2016). La legítima aplicación del derecho operacional en los procesos contra militares a propósito de la jurisdicción especial para la paz. Ciencia y Poder Aéreo, 11 (1), 82-91. Doi: http://dx.doi.org/10.18667/cienciaypoderaereo.527

\footnotetext{
${ }^{1}$ Artículo de reflexión, derivado de la investigación presentada como opción de grado para optar al título de Magíster en Derechos Humanos y Derecho Internacional de los Conflictos Armados de la Escuela Superior de Guerra. Bogotá, Colombia.
}

${ }^{2}$ Artigo de reflexão derivado da pesquisa apresentada como opção de graduação para obter o titulo de mestria em Direitos Humanos e Direito Internacional dos Conflitos Armados da Escola Superior de Guerra. Bogotá, Colômbia.

${ }^{3}$ Reflection article derived from the research presented as degree option to opt for the master degree In Human Rights and International Law of Armed Conflicts of the Colombia War College. Bogotá, Colombia.

${ }^{4}$ Abogada, Especialista en Derecho Penal. Defensora de miembros de las FFMM y Defensora pública. Correo electrónico: jullyandreamelolugo@hotmail. com
Resumen: las investigaciones judiciales contra militares ha sido un tema actual objeto de discusión por parte de la comunidad en general desde hace más de una década. Estas investigaciones realizadas por las autoridades judiciales abordan las funciones de los militares en el área de combate cuestionando así sus operaciones. Sin embargo, siendo estas el objetivo principal de los procesos judiciales, también debe serlo el análisis y la interpretación de las reglas que las rigen, esto es el Derecho Operacional. Este artículo analiza el Derecho Internacional Humanitario, su aplicación en Colombia, la legitimación que hace éste al Derecho Operacional, la normatividad utilizada en las investigaciones judiciales que se adelantan contra militares y a propósito de las conversaciones de Paz en la Habana, la normatividad que se pretende y espera aplique para los militares cuando de revisión y discusión sobre los resultados operacionales reportados se trate.

Palabras clave: derecho internacional humanitario; derecho operacional; procesos judiciales; justicia penal militar; justicia ordinaria; jurisdicción especial para la paz.

Resumo: as pesquisas judiciais contra militares tem sido um tema atual, objeto de discussão por parte da comunidade em geral desde faz mais de uma década. Essas pesquisas feitas pelas autoridades judiciais falam das funções dos militares na área de combate questionando assim suas operações. Porem, sendo essas o objetivo principal dos processos judiciais, também deve ser pelo o analise e a interpretação da regulamentação que as regem, isto é o Direito Operacional. Este artigo analisa o Direito Internacional Humanitário, sua aplicação na Colômbia, a legitimação que faz este ao Direito Operacional, a normatividade utilizada nas pesquisas judiciais que estão se fazendo contra militares, falando das conversas de paz em La Habana, a normatividade que se espera aplicar para os militares quando de revisão e discussão sobre os resultados operacionais reportados seja o caso.

Palavras-chave: direito internacional humanitário; direito operacional; processos judiciais; justiça penal militar; justiça ordinária; jurisdição especial para a paz.

Abstract: The judicial investigations against the military have been a current topic that has been the subject of discussion by the wider community for more than a decade. These investigations carried out by the judicial authorities address the functions of the military in the combat area thus questioning their operations. However, being these the main goal of the judicial processes must also be the analysis and the interpretation of the rules that govern them, this is the Operational Law. This article analyzes the International Humanitarian Law, its application in Colombia, the legitimation that this one does to the Operational Law, the normativity used in the judicial investigations that are advanced against the military and in connection with the Peace talks in Havana, the normativity that is intended and is expected to apply for the military when its about the review and discussion about the reported operational results.

Key Words: International Human Rights; Operational Law; Judicial Proceedings; Military Criminal Justice; Ordinary Justice; Special Jurisdiction for Peace. 


\section{Introducción}

Con el establecimiento de la Mesa de conversaciones en la Habana entre el gobierno Nacional y las FARC - EP, donde se busca alcanzar un acuerdo final para la terminación del conflicto que contribuya a la construcción de Paz, se elaboró una agenda que incluyó 6 puntos que buscan garantizar la efectividad del proceso y cumplir con las expectativas de la sociedad sobre un pronto acuerdo. (Acuerdo General - Mesa de conversaciones, 2012, en adelante El Acuerdo).

El punto cinco del Acuerdo, hace referencia a las Víctimas, punto que ha sido desarrollado y publicitado en el borrador conjunto del 15 de diciembre de 2015 como el acuerdo sobre víctimas del conflicto, denominado ya como sistema integral de verdad, justicia, reparación y no repetición. (SIVJRNR).

Este sistema integral, según se extrae del acuerdo sobre víctimas del conflicto, estará compuesto por cinco mecanismos, donde en materia de justicia se acordó la creación de la jurisdicción especial para la Paz constituida por una serie de salas, entre las que se incluye una Sala de Amnistía e Indulto y un Tribunal para la Paz, para administrar justicia e investigar, esclarecer, perseguir y sancionar las graves violaciones a los derechos humanos y las graves infracciones al Derecho Internacional Humanitario (Borrador Conjunto - Acuerdo sobre víctimas del conflicto, 2015, p. 7).

En este componente de justicia dentro del Acuerdo sobre víctimas (2015, p. 29), se crean unos principios básicos, dentro de estos en lo que tiene que ver con los agentes del Estado se establece un tratamiento especial, simultáneo, equilibrado y equitativo basado en el Derecho Internacional Humanitario. Dicho tratamiento diferenciado valorará lo establecido en las reglas operacionales de la fuerza pública en relación con el DIH. Ello quiere decir, que por primera vez se exigirá a las autoridades judiciales interpretar normas operacionales como ley especial en los casos de conductas cometidas por fuerza pública, cuando les sea aplicable.

Como se advierte, la Jurisdicción Especial para la Paz contempla la aplicación de reglas operacionales con lo que se garantizará que los miembros de la fuerza pública que se encuentren investigados por su participación en el desarrollo de operaciones militares, sean cuestionados desde el Derecho Operacional, normatividad que es ley especial para estos casos, lo que permitirá como consecuencia la aplicación del Derecho Internacional Humanitario, en atención al conflicto armado de carácter no internacional en el que se encuentra Colombia.
El propósito de éste artículo es resaltar la importancia que tiene en las investigaciones judiciales contra militares la aplicación del Derecho Operacional, ello con la finalidad de conocer cuál es el tratamiento que se les debe dar a las conductas de los militares cuando se aplica esta normatividad y cuál puede ser el resultado de la aplicación e interpretación de esta normatividad en los procesos.

\section{Problemática actual}

En Colombia actualmente existen dos órganos jurisdiccionales encargados de adelantar las investigaciones judiciales contra militares por efecto de sus resultados operacionales, el facultado para hacerlo en razón del fuero -entendido este en palabras de Velásquez (2012) como aquel privilegio del cual se goza por el ejercicio de un cargo puede ser oficial, mediante el cual se excepciona el principio general según el cual a todos los ciudadanos se les debe juzgar en igualdad de condiciones y sin hacer excepción alguna- es la Justicia Penal Militar, ente encargado de interpretar y aplicar las pautas que regulan el desarrollo de las operaciones militares por tener conocimiento de las mismas.

Sin embargo, dadas las denuncias contra militares acerca de las irregularidades en el desarrollo de sus operaciones han hecho que la competencia de juzgar sea remitida a la Justicia ordinaria, a través de la Dirección Nacional de Fiscalía especializada de Derechos Humanos y la Unidad de Contexto de la Fiscalía General de la Nación.

Es así como en el año 2007, en el informe preliminar de la Misión Internacional de Observación sobre Ejecuciones Extrajudiciales e Impunidad en Colombia, presentado por el Ministerio de Defensa Nacional, se afirmó que fueron muertos en combate 8.104 -presuntos guerrilleros- entre agosto de 2002 y septiembre de 2006 y que por estas muertes se presentaron quejas o denuncias por parte de familiares de estos presuntos guerrilleros (Informe preliminar de la Misión Internacional de Observación sobre Ejecuciones Extrajudiciales e Impunidad en Colombia, 2007) poniéndose así en duda la legalidad de las operaciones militares y perdiendo legitimidad la Justicia Penal Militar, haciéndose popular en el país la existencia de investigaciones judiciales contra militares por homicidios no en combate sino por homicidios en persona protegida, homicidios agravados, desaparición forzada y secuestro, entre otros.

Estando en el marco del Conflicto Armado Interno y dado el auge de las investigaciones judiciales contra los miembros de la Fuerza Pública por el desarrollo de las operaciones militares, se han revisado y estudiado las 
obligaciones que tiene el Estado Colombiano y sus agentes, en lo que tiene que ver con el respeto a los Derechos Humanos y al Derecho Internacional Humanitario (en adelante $\mathrm{DIH}$ ).

Ejemplo de lo anterior, se observa que, Jaimes A., \& Prieto R. (2012), afirmaron que todas las obligaciones en DIH provienen de una $u$ otra manera, del compromiso asumido por los Estados en el artículo $1^{\circ}$ común a los cuatro Convenios de Ginebra de 1949, a saber el de "respetar y hacer respetar" el conjunto de normas humanitarias, considerando que este deber ser enfocado a la obligación de prevención que le corresponde al Estado, prevención dicho por ellos, es determinante en la regulación jurídica de los conflictos armados, mediante la cual habrán de adoptarse entre otros, medidas legislativas y reglamentarias tendientes a prevenir las infracciones al $\mathrm{DIH}$ especialmente al interior de las Fuerzas Armadas y que como consecuencia de ello el DIH no podría estar aislado del derecho relativo a la conducción de hostilidades y/o el Derecho Operacional.

Además de la obligación de respeto, existe la responsabilidad de proteger ${ }^{5}$, destacada como la principal misión de las Naciones Unidas que ha sido encomendada a cada uno de los Estados, definida como:

El reconocimiento de los Estados de su deber primario de proteger a su propia población frente al genocidio, crímenes de guerra, depuración étnica y crímenes de lesa humanidad; y del deber subsidiario de la comunidad internacional para evitar o impedir su realización. La misma se irradia en 3 áreas de responsabilidad: de prevenir, reaccionary reconstruir (Añaños, 2009, p.168).

Como consecuencia de la responsabilidad de proteger, surge la obligación de implementar a nivel interno todos los recursos necesarios para salvaguardar la población de posibles afectaciones a su integridad personal, máxime si se tiene en cuenta el conflicto interno que vive Colombia y es allí donde cobra más importancia y relevancia el $\mathrm{DIH}$, pese a que ésta normatividad no es nueva, su implementación y difusión en Colombia aún está en proceso.

Cuando de Derecho Internacional Humanitario se habla, es común encontrarse con los conceptos de Derecho de Ginebra y Derecho de la Haya, ello por una razón básica, el DIH es el que los compila, fusiona e interdependiza.

\footnotetext{
${ }^{5}$ Esta responsabilidad de proteger en el derecho Internacional es conocida como el "R2P"
}

Por lo anterior, Ramírez (2010) al referirse al DIH cita esta definición:

El conjunto de normas internacionales, de origen convencional o consuetudinario, específicamente destinado a ser aplicado en los conflictos armados internacionales o no internacionales y que limita, por razones humanitarias, el derecho de las partes en conflicto a escoger libremente los métodos y los medios utilizados en la guerra (Derecho de la Haya), o que protege a las personas y a los bienes afectados (Derecho de Ginebra).

De igual forma, el Comité Internacional de la Cruz Roja (en adelante CICR) al definir DIH afirma:

Por DIH aplicable en los conflictos armados entiende las normas internacionales, de origen convencional o consuetudinario, especialmente destinadas a solucionar los problemas de índole humanitaria que se derivan directamente de los conflictos armados, internacionales o no, y limitan, por razones humanitarias, el derecho de las partes en conflicto a utilizar los métodos y medios de hacer la guerra de su elección (Derecho de la Haya) y protegen a las personas y los bienes afectados o que pueden verse afectados por el conflicto (Derecho de Ginebra) (CICR, 2005, p. 4).

El DIH comporta un número de reglas cuya finalidad es garantizar el alcance de su propia definición. Es decir, la protección de personas y la regulación de los medios y métodos para hacer la guerra, todo ello por efecto del conflicto armado.

Existen dos tipologías de conflicto armado y puede decirse que su diferencia radica en el ámbito territorial, pues en los dos persiste la misma situación de conflicto; mientras que en el Conflicto Armado Internacional (en adelante CAl) se enfrentan dos o más Estados o la lucha de un pueblo contra dominación colonial, ocupación extranjera o régimen racista, en el Conflicto Armado No Internacional (en adelante CANI) se enfrentan dentro del mismo territorio de un Estado, grupos que bien pueden ser las fuerzas armadas entre sí, o las fuerzas armadas contra grupos armados disidentes, o también entre grupos armados (Salmon, 2008).

Como se dijo, el DIH dispone un número de reglas y estas derivan de uno o más de sus principios, los cuales según Salmon (2004) representan el mínimo de humanidad aplicable en todo tiempo, en todo lugar y en toda circunstancia, válidos incluso para los Estados que no sean 
parte en los Convenios, dado que expresan la costumbre de los pueblos.

Asimismo, refiriéndose nuevamente a los principios afirma que:

Estos pueden encontrarse expresamente formulados en los tratados (como el referente a la distinción entre combatientes y población civil contenido en el artículo 48 del Protocolo Adicional I) o figurar de manera implícita (cuando el artículo 3 común a los cuatro convenios, partiendo de la obligación de distinción, protege a las personas que no participan directamente en las hostilidades) o encontrarse en la costumbre internacional (como la cláusula Martens, presente también en el preámbulo del convenio de la haya sobre medios y métodos del combate de 1907, en los artículos $62,63,142$ y 158 de los cuatro convenios de Ginebra respectivamente y en el artículo 1 del protocolo adicional I) (Salmón, 2004, p.52).

Del mismo modo, el CICR ha identificado cinco principios, sin que sean los únicos teniendo en cuenta que de ellos se desprenden mucho más, pero para este trabajo son los más relevantes: i). distinción, ii). proporcionalidad, iii). humanidad, iv). precaución, y v) respeto.

Se considera al principio de distinción como la columna vertebral del DIH, según el cual, las partes en conflicto deberán distinguir, en todo tiempo, entre civiles y combatientes, y pudiendo solo dirigir sus ataques contra éstos.

Al respecto, la Corte Interamericana de Derechos Humanos (en adelante ColDH) señala en sentencia Caso Masacre de Santo Domingo vs Colombia de 2012:

El principio de distinción se refiere a una norma consuetudinaria para conflictos armados internacionales y no internacionales en la cual se establece que" [l]as partes en conflicto deberán distinguir en todo momento entre personas civiles y combatientes", que "[l]os ataques sólo podrán dirigirse contra combatientes" y que "[l] os civiles no deben ser atacados". Además, son normas de Derecho Internacional Humanitario consuetudinario las que disponen que "[l]as partes en conflicto deberán hacer en todo momento la distinción entre bienes de carácter civil y objetivos militares", de tal forma que "los ataques sólo podrán dirigirse contra objetivos militares", mientras que "los bienes de carácter civil no deben ser atacados". Del mismo modo, el párrafo 2 del artículo 13 del Protocolo Adicional
Il a los Convenios de Ginebra prohíbe que tanto las personas civiles como la población civil como tal sean objeto de ataques.

De otra parte, el principio de proporcionalidad hace referencia a que el uso de la fuerza debe ser proporcional a la ventaja militar prevista y concreta, la CoIDH también hizo referencia a este principio en sentencia Caso Masacre de Santo Domingo vs Colombia de 2012:

El principio de proporcionalidad se refiere a una norma consuetudinaria para conflictos armados internacionales y no internacionales, en la cual se establece que "queda prohibido lanzar un ataque cuando sea de prever que cause incidentalmente muertos y heridos entre la población civil, daños a bienes de carácter civil o ambas cosas, que sean excesivos en relación con la ventaja militar concreta y directa prevista". El referido principio establece entonces una limitante a la finalidad de la guerra que prescribe que el uso de la fuerza no debe ser desproporcionado, limitándolo a lo indispensable para conseguir la ventaja militar perseguida.

Igualmente, el principio de humanidad precisa que el ataque no debe generar males superfluos y daños y sufrimientos innecesarios, que en los métodos y medios para hacer la guerra deben resultar siempre de un mínimo de humanidad.

Consecuente con la definición de Humanidad propuesta, en sentencia el Tribunal Penal Internacional para la ex Yugoslavia en el asunto Tadic en 1996, declaró que:

De hecho, las consideraciones elementales de humanidad y de sentido común hacen absurdo pensar que los Estados puedan emplear armas prohibidas en los conflictos armados internacionales cuando tratan de reprimir una rebelión de sus propios ciudadanos en su territorio interno. Lo que es inhumano y, por ende, está prohibido en los conflictos internacionales no puede considerarse humano y admisible en los conflictos de civiles.

Asimismo, el principio de precaución hace alusión a todas las medidas previas que se tienen que tomar antes de realizar un ataque, ello con la finalidad de garantizar entre otros, los principios de distinción, humanidad y proporcionalidad, revistiéndose de gran importancia este principio por ser el primero a tener en cuenta al momento de un combate. 
A propósito de éste principio, el Protocolo Adicional I a los Cuatro Convenios de Ginebra, en su artículo 82 establece que las partes en conflicto podrán contar con la asesoría jurídica para la correcta aplicación de los convenios y para su enseñanza a las Fuerzas Militares (en adelante FF.MM.), normativa que fue resaltada por la Dirección de Derechos Humanos del Ministerio de Defensa (2013).

Finalmente, está el principio de respeto, referido por el CICR como aquel que debe tenerse a quienes estén prestando ayuda humanitaria y religiosa, buscando proteger así la labor de quienes se preocupan por las consecuencias que sobre la humanidad produce un conflicto armado.

\section{Aplicación del DIH en Colombia}

Se puede afirmar con base en su definición, que el DIH adquiere legitimidad cuando se presenta una situación de Conflicto Armado. Es por ello, que para poder predicar su aplicación en Colombia se resalta la existencia del Conflicto Armado no internacional en que se encuentra el País.

Al analizar la existencia del conflicto armado en Colombia la Honorable Corte Constitucional en providencia del 2012, refirió la concepción amplia de conflicto armado, sobreponiéndola a su noción estrecha por cuanto ésta limita a un conjunto específico de acciones y actores armados, lo caracteriza por el uso de ciertas armas y medios de guerra, o lo circunscribe a áreas geográficas específicas, vulnerando los derechos de las víctimas.

Dado lo anterior, considera la Corte en ésta misma decisión, que una definición estrecha reduce las posibilidades de cumplimiento del deber de prevención, atención y protección que deben brindar las autoridades a todos los habitantes del territorio colombiano frente a actos violentos y reduce la capacidad de las autoridades militares y de policía para enfrentar este fenómeno, así como las posibilidades de las autoridades judiciales de sancionar a los victimarios.

Las decisiones de la Honorable Corte Constitucional, donde se ha abordado la situación de conflicto armado interno, (C-781 de 2012, C- 250 de 2012, C-462 de 2013, C-280 de 2013) coinciden en afirmar que éste existe ya de vieja data en Colombia, de allí que se creen límites temporales cuando de reparación a víctimas que con ocasión del conflicto armado existan.

Asimismo, la situación de conflicto armado existente en Colombia, ha sido afirmada por diferentes autores, entre ellos Nasi \& Rettberg (2005) quienes sostienen al igual que
Mejía (2007) que el conflicto armado en Colombia es un hecho y ya ha superado medio siglo de duración.

Ahora bien, le asiste razón a Nieto (2008), cuando resalta que independiente de la existencia o no de un conflicto armado de carácter no internacional, lo cierto es que Colombia es parte en los Convenios de Ginebra y en los Protocolos I y II que se aplican a los conflictos armados de carácter internacional y de carácter interno. Además, la Constitución Política tiene una extensa carta de Derechos Humanos que, adicionalmente, se amplía con aquellos que a través del bloque de constitucionalidad conforman la legislación interna.

Adicionalmente, el Código Penal Colombiano contempla como delitos de orden interno la mayoría de las infracciones graves y no graves del $\mathrm{DIH}$, tales como el genocidio (aplicable aun en los casos en que no hay conflicto interno), y los que denominan delitos contra Personas y Bienes Protegidos por el Derecho Internacional Humanitario. De manera que las operaciones militares de las Fuerzas Armadas y también las de los sublevados están sujetas, independientemente del $\mathrm{DIH}$, al régimen penal. Por consiguiente, considérese que haya o no conflicto interno, el DIH es plenamente aplicable en Colombia (Nieto, 2008, p. 157).

Aparte de las anteriores muestras de aplicación del $\mathrm{DIH}$ en Colombia, se destaca que los principios de éste se han venido implementando al interior de las FF.MM.

De tal modo, el principio de precaución se visibiliza entre otros, mediante la creación de los Asesores Jurídicos Operacionales - AJOPE - cuya función principal es asesorar a los comandantes militares en la toma de decisiones, deben ser abogados que asesoren en materia de DD.HH., DIH y Derecho Operacional en el proceso de planeación, ejecución y evaluación de las operaciones militares (Dirección de Derechos Humanos del Ministerio de Defensa, 2013).

Igualmente, la existencia de reglas de enfrentamiento (en adelante ROE), son representativas de la implementación del principio de precaución, además de atender los principios de distinción y proporcionalidad; definidas como un mecanismo básico para que los mandos superiores decidan cuando se debe desplegar una fuerza militar y cuanta fuerza se puede emplear. Determinar el grado y las modalidades de aplicación de la fuerza, así como los límites dentro de los cuales puede actuar un jefe. Se pueden trazar reglas de enfrentamiento para restringir acciones concretas o para ampliar los límites de una acción, sin dejar de aplicar el derecho internacional. Las reglas de enfrentamiento son la suma de varios fac- 
tores, que incluyen el marco jurídico de las operaciones, instrucciones políticas y misión militar (Gómez, 2006).

Sumado a lo anterior, las ROE son consideradas como una de las obligaciones para las autoridades encargadas de hacer cumplir la ley y evitar homicidios en persona protegida (directrices del Comando General de las FFMM sobre Derechos Humanos y DIH en Colombia, 2008).

\section{Al respecto se afirmó:}

Se entienden las mismas como la herramienta principal utilizada para la regulación del uso de la fuerza y sirve como piedra angular de la disciplina del Derecho Operacional. Su fundamento parte de la observancia del Derecho consuetudinario y convencional en cuanto al derecho de la legítima defensa y el Derecho de la Guerra.

Otros aspectos que juegan un papel esencial en la elaboración y cumplimiento de las Reglas de Enfrentamiento, son los objetivos y las limitaciones tanto de tipo político como militar (Ayala, 2009, p. 4).

Además de lo anterior, en el año 2009 el Comando General de las FF.MM. presentó un manual de Derecho Operacional, primero en la historia del país, donde entre otros asuntos se compilan los principios del DIH resaltados en este trabajo, se amplía su contexto y se implementa todo lo concerniente al planeamiento, ejecución y evaluación de las operaciones militares.

Consecuente con la existencia de un manual de Derecho Operacional en Colombia y pese a que algunos estudiosos consideran que éste no existe, hay suficientes bases doctrinarias que permiten defender su existencia además del Manual referido, para admitir que la conducción de hostilidades hace parte del mundo del Derecho.

Es así, como el Derecho Operacional ha sido definido como el conjunto de normas que especifican las circunstancias y limitaciones mediante las cuales la autoridad superior mantiene el control sobre el uso de la fuerza para el cumplimiento de la misión y que, a la vez, se utilizan para controlar las acciones que podrían interpretarse como provocativas o que generen una escalada por potenciales oponentes (Niemann, 2001)

A su vez, el Comando General de las FF.MM. de Colombia estableció:

Hay un amplio espectro de principios y normas que regulan el uso de la fuerza, desde el marco básico que es la Constitución Política con los correspondientes tratados y convenios sobre $\mathrm{DDHH}$ y DIH ratificados por Colombia hasta el nivel táctico de las reglas de enfrentamiento, pasando por todo el entramado de leyes que constituye el sistema legal colombiano. De ahí la necesidad de desarrollar un verdadero Derecho Operacional, que no es otra cosa que la aplicación ordenada de todas estas normas al planeamiento, la ejecución y la evaluación de las operaciones de la Fuerza Pública (Manual de Derecho Operacional 2009, p. 4).

Como se viene analizando, el Derecho Operacional en Colombia, hace parte de la política integral de DD.HH. y DIH del Ministerio de Defensa Nacional, por medio de ésta normativa se han implementado los principios del DIH en la preparación, ejecución y evaluación de las operaciones de la fuerza pública.

De ésta manera, al Ministerio de Defensa Nacional (2010) al referirse al manual de Derecho Operacional afirmó que éste, por un lado, ofrece las herramientas jurídicas necesarias para ayudar a los miembros de las Fuerzas Militares a asegurar la juridicidad de las operaciones; y por el otro, facilita el acceso a un compendio que presenta de manera ordenada las normas nacionales e internacionales y la doctrina operacional aplicable a la conducción de operaciones militares.

Por ello, si las investigaciones se centran en cuestionar las operaciones militares mediante las cuales se obtienen resultados operacionales, es imperativo que dichas investigaciones se concentren en la interacción y verificación sobre la aplicación de dicha normativa operacional por parte de las FF.MM. en sus actividades tácticas especialmente.

Una vez se lleve a cabo esta interacción, podrá determinarse por parte de la autoridad Jurisdiccional si una operación militar se compadece o no con los principios del DIH y toda su normativa, para finalmente establecer si ésta fue legítima, y como consecuencia inmediata de ello, disponer bien sea de la preclusión de la investigación, archivo de las diligencias, cesación del procedimiento o remisión por competencia a la Justicia Penal Militar, según sea el caso y el carácter de la autoridad a cargo de la investigación.

Acertadamente Padilla (2009) aseguró que el manual de Derecho Operacional, además de dar claridad a los comandantes de las Fuerzas sobre procedimientos, también se convierte en una guía indispensable para la justicia ordinaria, pues provee herramientas que ayudan a los miembros de las Fuerzas Militares a asegurar la juridicidad de las operaciones y facilitan el acceso a un compendio 
que presenta de manera ordenada las normas nacionales e internacionales y la doctrina operacional aplicable a la conducción de operaciones militares.

De esta manera, sin importar la autoridad judicial que conozca de un proceso penal contra algún o algunos militares, las operaciones militares serían interpretadas y entendidas de manera acertada, toda vez que al ser el Derecho Operacional la compilación a nivel interno de los principios y normatividad establecidos por el DIH para la planeamiento, ejecución y seguimiento de las operaciones militares, podrá determinarse con autoridad si una operación militar acogió en debida forma el DIH y como consecuencia de ello los militares actuaron en ejercicio legítimo de su misión constitucional.

Consecuente con lo anterior, es necesario como lo afirma Ayala (2012), que tanto quienes puedan tener competencia para investigar militares, bien sea en razón del fuero o por remisiones a la Justicia Ordinaria, como los militares que participen en la preparación, ejecución y seguimiento de una operación militar, cuenten con la debida capacitación y conocimiento en DIH y como consecuencia en Derecho Operacional.

Corolario con todo lo anterior, y en atención a la futura implementación de la Jurisdicción especial para la Paz, surge una tercera jurisdicción que conocería de las investigaciones contra militares.

Dicha Jurisdicción Especial, como se dijo $a b$ initio, hace parte del acuerdo sobre víctimas del conflicto y aparece en el componente de justicia donde dentro de los principios básicos, refiere que para los agentes del Estado se establece un tratamiento especial, simultáneo, equilibrado y equitativo basado en el Derecho Internacional Humanitario. Dicho tratamiento diferenciado valorará lo establecido en las reglas operacionales de la fuerza pública en relación con el DIH.

Esto reviste de gran importancia la existencia y aplicación del Derecho Operacional en Colombia, teniendo en cuenta que se convertirá en parámetro obligatorio para la investigación en los procesos judiciales que se adelanten contra los miembros de la fuerza pública.

Pese a que poco se sabe sobre el procedimiento como tal que regulará la Jurisdicción Especial para la Paz, se sabe que las operaciones militares donde se produjeron bajas especialmente, harán parte de ésta, reconociéndose el debido proceso y existiendo la presunción de legalidad y legitimidad de dichas operaciones militares.
Dado lo anterior, se firmó el - documento compromiso del gobierno nacional en el marco del fin del conflicto armado, para la aplicación de la jurisdicción especial para la paz a los "agentes del estado"-, publicado para el mes de diciembre de 2015, documento donde además de reivindicar el papel de las fuerzas militares como defensores de los colombianos, se trazan unos lineamientos que buscan garantizar la seguridad jurídica para los agentes del Estado.

Dentro de estos lineamientos se fijó como eje central de las investigaciones, la aplicación del Derecho Internacional Humanitario y el Derecho Operacional, lineamiento concretamente contenido en el punto 7 del documento referido:

7. Responsabilidad del mando y otros superiores: La Jurisdicción Especial para la Paz aplicará, en el caso de los miembros de la Fuerza Pública, el Derecho Internacional Humanitario y las reglas operacionales de la Fuerza Pública en relación con el $\mathrm{DIH}$, como ley especial. La determinación de la responsabilidad del mando no podrá fundarse exclusivamente en el rango, la jerarquía, o el ámbito de jurisdicción. (Compromiso del Gobierno Nacional en el marco del fin del conflicto armado, para la aplicación de la Jurisdicción Especial para la Paz a los "agentes del estado", 2015).

Con este avance en Colombia sobre la obligatoria aplicación e interpretación del Derecho Operacional a luz del DIH en Colombia, se advierte la necesidad de que los integrantes de la jurisdicción especial, conozcan las reglas operacionales, ello en concordancia entonces con el Derecho Operacional y todo lo que en extenso se refiere en el presente artículo al respecto.

Este lineamiento reafirma el carácter de acto administrativo del que gozan las operaciones militares, y por lo mismo, su presunción de legalidad. Al respecto Mejía (2015) afirmó que este criterio implica que toda operación militar en Colombia deberá ser analizada, como desarrollo del marco constitucional (legitimidad y legalidad), de un acto administrativo complejo de naturaleza especial. Legalidad, como fruto de un mandato cualificado del pueblo en donde intervienen principios del $\mathrm{DIH}$ y los $\mathrm{DDHH}$ que sólo desde una comprensión integral pueden mostrar cómo se utilizó la fuerza dentro de una guerra, entre otros que destaca el autor.

De igual manera, Mejía (2005) refiriéndose concretamente al Derecho Operacional sostiene que es esencial tener presente el rol esencial de un militar en el nivel táctico frente a la comisión de una conducta bajo la jurisdicción 
para la Paz y que sin el Derecho Operacional no se podrá entender el andamiaje colombiano existente para el uso de la fuerza y denota la importancia que el Derecho Operacional implica en la jurisdicción, ya que no existe ningún precedente en el mundo de donde se puedan "trasplantar" estas experiencias.

Además, de la publicación sobre la Jurisdicción Especial para la Paz a los agentes del Estado (2015), fue publicada en la página de la presidencia una hoja de datos que refiere la aplicación de la Jurisdicción Especial para la Paz a los agentes del Estado (2015) reafirmando lo aquí dicho sobre la interpretación y uso del Derecho Internacional Humanitario y el Derecho Operacional donde refiere también que este criterio exige reconocer que las Fuerzas Militares pueden tomar la ofensiva contra blancos legítimos, pueden actuar por sorpresa y pueden usar su capacidad militar superior.

Se considera que con lo anterior, y con el contenido completo del último documento referenciado, no sólo se está legitimando verdaderamente el Derecho Operacional en Colombia, tarea que no ha sido fácil ante los operadores de justicia ordinaria, también se está legitimando el accionar de los militares y sus operaciones en el terreno, avance muy significativo para quienes defienden y representan la defensa de estos hombres.

\section{Conclusiones}

En el desarrollo del presente artículo se ha podido establecer el planteamiento central del cual partió la investigación: Es legítima la aplicación del Derecho Operacional y por consiguiente del DIH a los procesos judiciales contra militares.

El DIH es un derecho aplicable a los conflictos armados de carácter no internacional, Colombia no sólo ha reconocido estar en situación de conflicto armado, también ha venido implementando las normas y los principios del $\mathrm{DIH}$, adoptando incluso un manual de Derecho Operacional, por ello se puede concluir en el presente artículo que:

Teniendo como base el desarrollo de operaciones militares generadas por efecto del conflicto armado se hace legítima y necesaria la aplicación e interpretación del Derecho Operacional en las investigaciones judiciales contra las FF.MM.

Además de ello, es evidente que cuando se aplica el Derecho Operacional a procesos contra militares, una consecuencia de ello puede ser su remisión a la Justicia Penal Militar para que se continúe investigando.
Por lo anterior, es importante que cualquier autoridad Jurisdiccional en materia penal se encuentre en la capacidad de aplicar el Derecho Operacional al punto de evidenciar su falta de competencia para continuar investigando, si se trata de un Juez ordinario.

Y ahora con la implementación de la Jurisdicción Especial para la Paz, se tiene como cierta la importancia, necesidad y obligatoriedad del uso, interpretación y aplicación del Derecho Operacional en las investigaciones contra militares.

Para resumir, existe en Colombia un derecho aplicable a las investigaciones judiciales contra militares, cuando por efecto del conflicto armado desarrollan una operación que termina siendo investigada por diversas autoridades judiciales, la aplicación de ese derecho, permite la correcta revisión de una operación militar y la garantía de una decisión ajustada a Derecho y dotada de seguridad jurídica.

\section{Referencias}

Acuerdo General-Borrador Conjunto. Víctimas (Diciembre 15, 2015). Recuperado el 17 de junio de 2015, https://www.mesadeconversaciones.com.co/sites/default/files/borrador-conjunto-acuerdo-sobre-las-victimas-del-conflicto-1450190262. pdf

Acuerdo General - Mesa de conversaciones (Agosto 26, 2012). Recuperado el 15 mayo de 2014, https://www.mesadeconversaciones.com.co/sites/default/files/AcuerdoGeneralTerminacionConflicto.pdf

Añaños, M. (2009). La responsabilidad de proteger en naciones unidas y la doctrina de la "responsabilidad de proteger". UNISCI Discussion Papers, (21) 164-192.

Ayala, J. (2012) El proyecto de acto legislativo 192 de 2012: ¿Por qué investigar en el marco del derecho internacional humanitario"?. Cuadernos de Derecho Penal, 8, 61-78.

Comando General de las FF.MM. (2008). Directrices del Comando General de las FFMM sobre Derechos Humanos y DIH en Colombia.

Comando General Fuerzas Militares (b). (2009). Manual FF.MM3-41 Público. Manual de Derecho Operacional. Primera Edición. Bogotá.

Comité Internacional de la Cruz Roja. (2005).

Corte Constitucional (Julio 2013). Sentencia C-462/12. Magistrado ponente: Mauricio González Cuervo. Referencia: expediente D-9362. Bogotá D.C.

Corte Constitucional (mayo 2013). Sentencia C-280/13. Magistrado ponente: Nilson Pinilla Pinilla. Referencia: expediente D-9321. Bogotá D.C. 
Corte Constitucional (octubre 2012). Sentencia C-250/12. Magistrado ponente: Humberto Antonio Sierra Porto. Referencia: expediente D-8590 - D-8613 Y d-8614 acumulados Bogotá D.C.

Corte Constitucional (octubre 2012). Sentencia C-781/12. Magistrada ponente: María Victoria Calle Correa. Referencia: expediente D-8997. Bogotá D.C.

Corte Interamericana de Derechos Humanos (Noviembre, 2012). Caso Masacre de Santo Domingo vs Colombia.

Gómez, J. (2006) Las reglas de enfrentamiento y la posibilidad de su elaboración, difusión y aplicación en Colombia. Fuerza Armada Nacional. Recuperado el 18 de septiembre de 2014, https:// www.fac.mil.co/?idcategoria $=7205$

Informe preliminar de la Misión Internacional de Observación sobre Ejecuciones Extrajudiciales e Impunidad en Colombia (2007).

Jaimes, M. \& Prieto, R. (2012). Violaciones al derecho internacional humanitario: prevenir, antes que sancionar. Universitas, (124) 119-145.

Jurisdicción Especial para los agentes del Estado (Diciembre 19, 2015). Recuperado el 18 de junio de 2016, http://www.indepaz.org.co/wp-content/uploads/2015/12/JEP-PARA-AGENTES-DEL-ESTADO-ACUERDO.pdf

Jurisdicción Especial para la Paz a los agentes del Estado (Diciembre 19, 2015). Recuperado el 18 de junio de 2016, http:// es.presidencia.gov.co/saladeprensa/Documents/JEP\%20 para\%20agentes\%20del\%20Estado\%20.pdf

Mejía, J. (2007). Derechos Humanos, conflicto armado y agresión terrorista en Colombia. Prolegómenos. Derechos y Valores, $X$ (19) $51-88$.

Mejía, J. (2015). El Derecho Operacional deberá ser tenido en cuenta por la jurisdicción para la Paz. Recuperado el 20 de diciembre de 2015, http://costanoticias.com/el-derecho-operacionaldebera-ser-tenido-en-cuenta-por-la-jurisdiccion-para-lapaz/

Ministerio de Defensa Nacional (2010). Avance en el cumplimiento de las 15 medidas adoptadas por el Ministerio de Defensa Nacional, noviembre 2008 - abril 2010. Recuperado el 18 de noviembre de 2014, http://www.gsed.gov.co/irj/go/km/docs/ Mindefensa/Documentos/descargas/Asuntos_de_Interes/ Derechos_Humanos/docs_nweb/Avances_Caso_Soacha. pdf

Ministerio de Defensa Nacional (2013). Rol del Asesor Jurídico Operacional Lo que importa no es fundamentar los derechos, sino protegerlos. Boletín Oda (2).

Nasi, C. \& Rettberg, A. (2005). Los estudios sobre conflicto armado y paz: un campo en evolución permanente. Colombia Internacional, (62) 64 - 85.

Niemann, F. (2001) las reglas de enfrentamiento y el papel del abogado militar, Una perspectiva operacional. Recuperado el 15 de noviembre de 2015, http://www.revistamarina.cl/ revistas/2001/5/Niemann.pdf

Nieto, R. (2008). ¿Hay o no hay conflicto armado en Colombia? Anuario colombiano de derecho internacional ACDI, 1(1), 139159.

Padilla, F. (2009) Manual de Derecho Operacional también es una guía para la justicia ordinaria: General Padilla de León. Secretaria de prensa presidencia de la República de Colombia. Recuperado el 15 de noviembre de 2014, http://web.presidencia. gov.co/sp/2009/diciembre/21/13212009.html

Ramírez Lamy, Andrea. (2010). Diferencias teóricoprácticas entre Derechos Humanos y Derecho Internacional Humanitario. Via luris, Enero-Junio, 93-122.

Salmón, E. (2004). Introducción al derecho internacional humanitario. ( $2^{\mathrm{a}}$ ed.). Lima: Fondo Editorial de la Universidad Católica del Perú.

Salmón, E. (2008). Introducción al derecho internacional humanitario. Lima: Fondo Editorial de la Universidad Católica del Perú.

Tribunal Penal Internacional para la Ex Yugoslavia (noviembre de 1996) caso Tadic

Velásquez, F. (2012). Apuntes generales sobre el proyecto de acto legislativo 16 de 2012 senado, 192 de 2012 cámara. Cuadernos de Derecho Penal, 8, 61-78. 